\title{
Evolutionary and environmental influences on human lactation
}

\author{
BY ANDREW M. PRENTICE AND ANN PRENTICE \\ MRC Dunn Nutrition Unit, Milton Road, Cambridge CB4 1 XJ
}

The evolution of lactation as a strategy by which mothers can continue to nourish their offspring after birth is of such profound significance that it forms the very basis for identifying a whole class of vertebrates, the Mammalia. Although certain non-mammals also feed their young by maternal secretion of nutrients, it is only the mammals that have developed specific cutaneous secretory organs, the mammary glands. The philogenic origins of these, now highly developed, glands are thought to have arisen from the selective modification of apocrine sweat glands (Mepham, 1987). Divergent evolution has since resulted in wide variations in the number, morphology and anatomy of mammary glands, ranging from the teatless abdominal pouches of egg-laying monotremes to the highly-developed udder of the dairy cow capable of remarkable feats of biosynthesis. The present paper considers how evolutionary factors may have shaped the development of human lactation and how these now influence the way in which lactation is affected by environmental variables; primarily the nutrition of the mother.

\section{EVOLUTIONARY INFLUENCES ON HUMAN LACTATION}

In addition to the wide variation in the physical characteristics of mammary glands between species there is also wide divergence in the biological strategies adopted for lactation. These are revealed as differences in variables such as the relative duration of gestation and lactation (altricial $v$. precocial birth), the quantity and composition of milk produced, and maternal feeding strategies during lactation (Mepham, 1987). To review these across all mammals would be beyond the scope of the present review, so we have chosen to concentrate on aspects of milk quantity and composition in a small selection of the eutherian mammals. We have included 'laboratory' and domesticated animals since the study of such species has been the source of much of our current knowledge on lactation.

Fig. 1 illustrates the concentrations of macronutrients in milks from eight species ranked according to protein content, and divided into laboratory animals, domesticated animals and primates. It is clear that the mammary gland is a highly adaptable organ capable of producing milk over a wide range of composition. Inclusion of other species would reveal an even greater range, with a number of seals producing milk containing up to $500 \mathrm{~g} \mathrm{fat} / \mathrm{kg}$ and negligible milk sugar. It seems reasonable to assume that the composition of milk in any species has evolved to suit that species, and may represent a compromise between the nutritional stress which is sustainable by the mother and the optimal growth and development needs of the offspring.

The 10 -fold variation in protein concentrations in Fig. 1 (which reduces to a 5-fold range if expressed as protein energy \%) is related to the postnatal growth rates of each species with the fastest growing young receiving the most concentrated milk. Fat concentration is approximately correlated with protein, thus providing energy to support rapid growth where necessary. Milk sugars (mostly lactose) tend to be negatively 

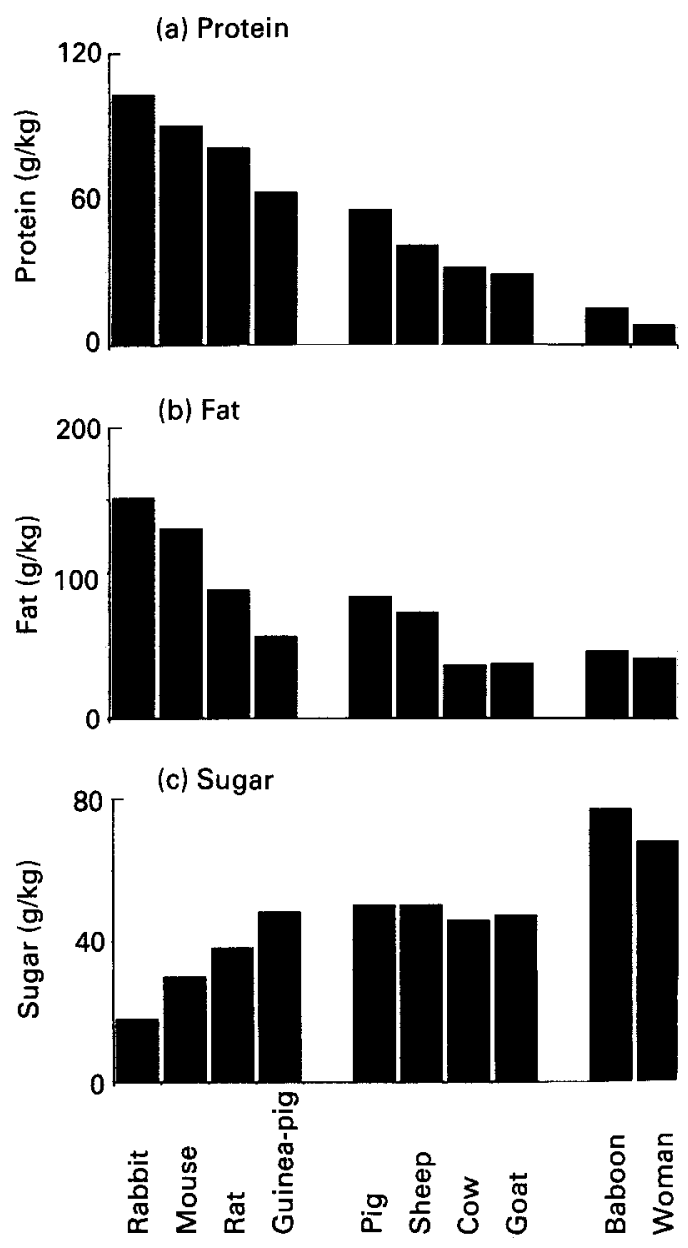

Fig. 1. Variations in macronutrient concentration in milks from various species. Data from Oftedal (1984).

correlated with fat and protein. This is partly because milk is iso-osmotic with plasma, which means that alterations in composition must be achieved within a fixed overall solute concentration. Vitamin and mineral concentrations also vary widely across species. This is illustrated for $\mathrm{Ca}$ in Fig. 2 where there is a 30 -fold range. Note that milk $\mathrm{Ca}$ tends to correlate with milk protein due to the fact that casein binds $\mathrm{Ca}$ and because high growth rates demand a high $\mathrm{Ca}$ intake.

The amount of milk produced also varies widely across species, even when adjusted for maternal metabolic body size by allometric scaling (Oftedal, 1984). By combining estimates of the amount of milk produced at peak lactation with its nutrient content it is possible to calculate the relative daily nutritional stress of lactation on the mother. This is illustrated for energy in Fig. 3, which again reveals the cross-species diversity of lactation with a 15-fold range. Oftedal (1984) has identified three allometric groupings divided by 'grade shifts' representing quite different lactational strategies. The grouping with the highest energy demand relative to maternal metabolic body size contains species with 


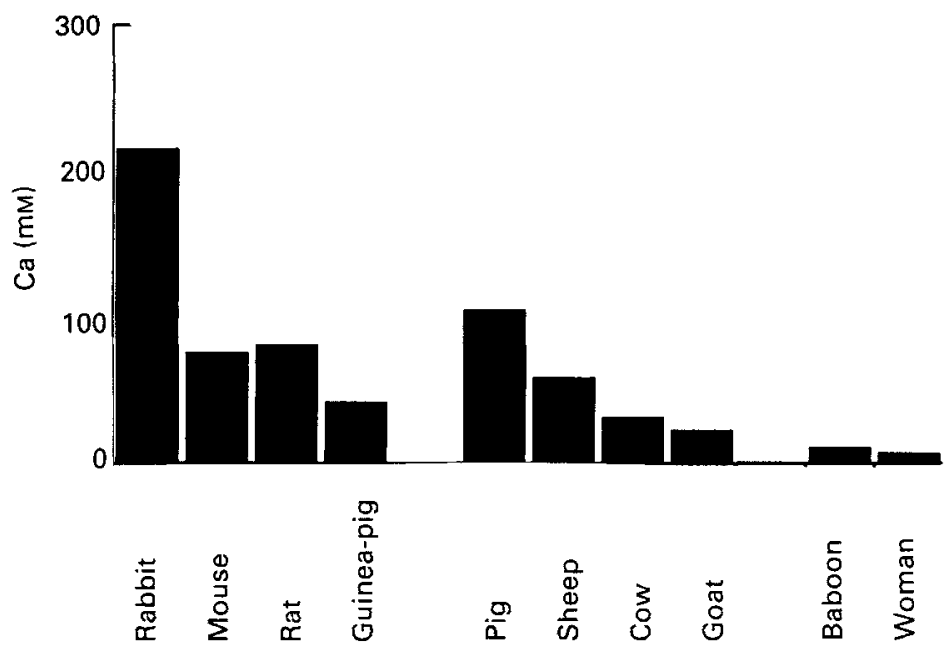

Fig. 2. Variations in calcium concentration in milks from various species. Data from Mepham (1987) and supplementary sources.

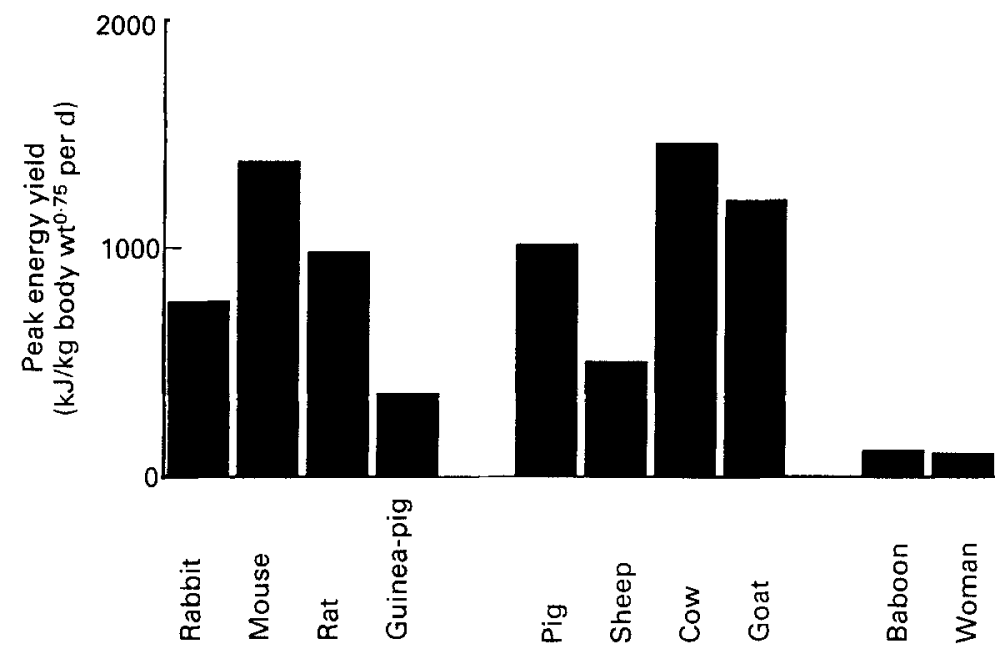

Fig. 3. Comparisons of the energetic stress of lactation expressed per unit time. Data from Oftedal (1984).

large litters of fast-growing young. The second grouping contains ungulates which often have multiple young, and the lowest grouping contains the primates which usually bear a single slow-growing young.

A key feature of Figs. 1-3 is that humans stand out as producing milk with a very low nutrient density (with the exception of lactose), and as having a very low stress of lactation. It is usually assumed that this lactational strategy has been determined by the very slow growth rate of the human infant (Brody, 1945), which in turn has been naturally selected as providing optimal time for the growth, development and training of a large brain (Martin, 1980). The low stress of lactation per unit time means that the incremental food intake required by a lactating woman is much lower than that for most 
non-primates. This allows women to adopt a number of different mechanisms to re-balance their energy and nutrient budgets in lactation and liberates them from the obligate need, incumbent on most other species, to markedly increase food intake (Prentice \& Whitehead, 1987).

Although the stress per unit time of lactation is low for humans the total cost, at least in terms of energy, is high since the mother has to supply the maintenance needs, in addition to the growth needs, of the infant over a long period. A similar analysis can be performed for gestation and yields a similar picture of low stress but high total costs in women (Prentice \& Whitehead, 1987). This is important since the high level of maternal investment in a baby and the very slow human reproductive cycle commit a mother to sustaining each conception even when nutritional conditions are severely sub-optimal. This is particularly true in lactation since the mother has already invested heavily throughout gestation. The implications of this in terms of the resilience of human lactation is discussed below.

\section{ENVIRONMENTAL INFLUENCES ON HUMAN LACTATION}

In addition to the most important factor, maternal nutrition, there are several other environmental influences which might affect human lactational performance. These include: climatic conditions (mediated via effects on maternal water balance), maternal work patterns (mediated via effects on energy balance, fatigue, and time available for feeding the baby), maternal and infant infections, and cultural attitudes to breast-feeding patterns and duration.

We have investigated many of these effects in our studies of marginally-nourished rural women in The Gambia. A recurring feature of these investigations has been that lactational performance appears to be exceptionally resilient to many of these influences (Prentice et al. 1986). For instance, milk synthesis was largely unaffected by maternal fasting during Ramadan when women consumed no food or fluids between 04.00 and 19.00 hours, and lost an average of $7 \%$ of body weight from morning to evening (Prentice et al. 1984). Similarly, milk output declines by only $10 \%$ in the annual hungry season during which the mothers are working extremely hard in the fields (at physical activity levels of $2 \cdot 1 \times \mathrm{BMR}$ ), are in negative energy balance mobilizing $50 \mathrm{~g}$ body fat $/ \mathrm{d}$, are separated from their infants for up to $8 \mathrm{~h} / \mathrm{d}$, thus interrupting the usual demandfeeding patterns, and have infants with raised levels of infections and consequent inanition which reduces the demand for milk (Prentice et al. 1986). This impression of the robustness of human lactation is reinforced by the available worid literature which reveals few credible examples of lactatıonal performance being severely impaired by non-nutritional environmental influences. Consequently the remainder of the present paper will focus on the link between maternal nutrition and lactational performance.

\section{Influence of maternal nutrition on milk volume}

The impression gleaned from older literature (Fig. $4(a)$ ) is that undernourished women from developing countries $p$ oduce only about half as much milk as women from affluent countries at 3 months postpartum. However, more recent literature (Fig $4(b)$ ) reveals a quite different picture in wh ch there is no apparent distunction between the two. We have concluded that the explanation for tis difference is methodological since the 

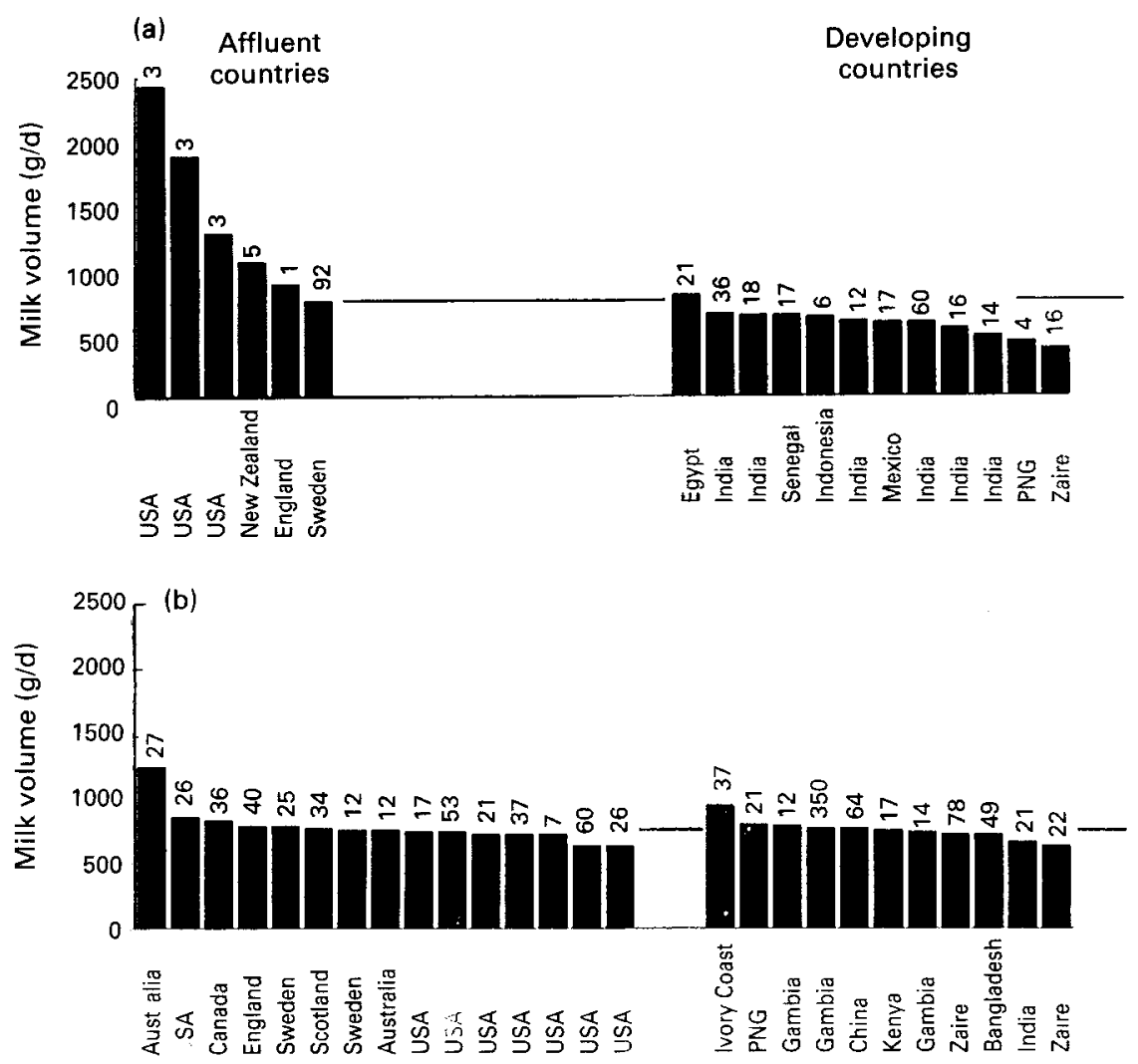

Fig. 4. Milk output at peak lactation in women from affuent and developing countries. All data from exclusive breast-feeders at 3 months postpartum. (a), Reports before 1974; (b), reports subsequent to 1974. Values given are no. of subjects. PNG, Papua New Guinea.

earlier studies used highly-selected samples of women in affluent countries (including professional wet-nurses) and often used culturally-insensitive measurement procedures in developing countries. These included the admission of unsophisticated rural women into intimidating metabolic wards and imposing timed feeding schedules which prohibited night feeds. More recent studies which have appreciated the importance of not interfering with demand-feeding patterns, or have used unobtrusive stable-isotope tracer m:thods, consistently yield higher milk intakes and suggest a remarkable level of similarity between affluent and poor women. Fig. 5 shows data collected by the same research team using similar techniques in the two different settings of The Gambia and UK (Prentice et al. 1986). Milk outputs at peak lactation are very similar, and because of sustained demand feeding The Gambian values are higher in later lactation.

We have extended this analysis by investigating the relationship between maternal nutritional status and milk output or energy content (Prentice et al. 1994b). The results are illustrated in Fig 6 in which nutritional status is indicated by maternal BMI. One set of data is excluded; this is from Zaire in which very low milk volumes are repeatedly 


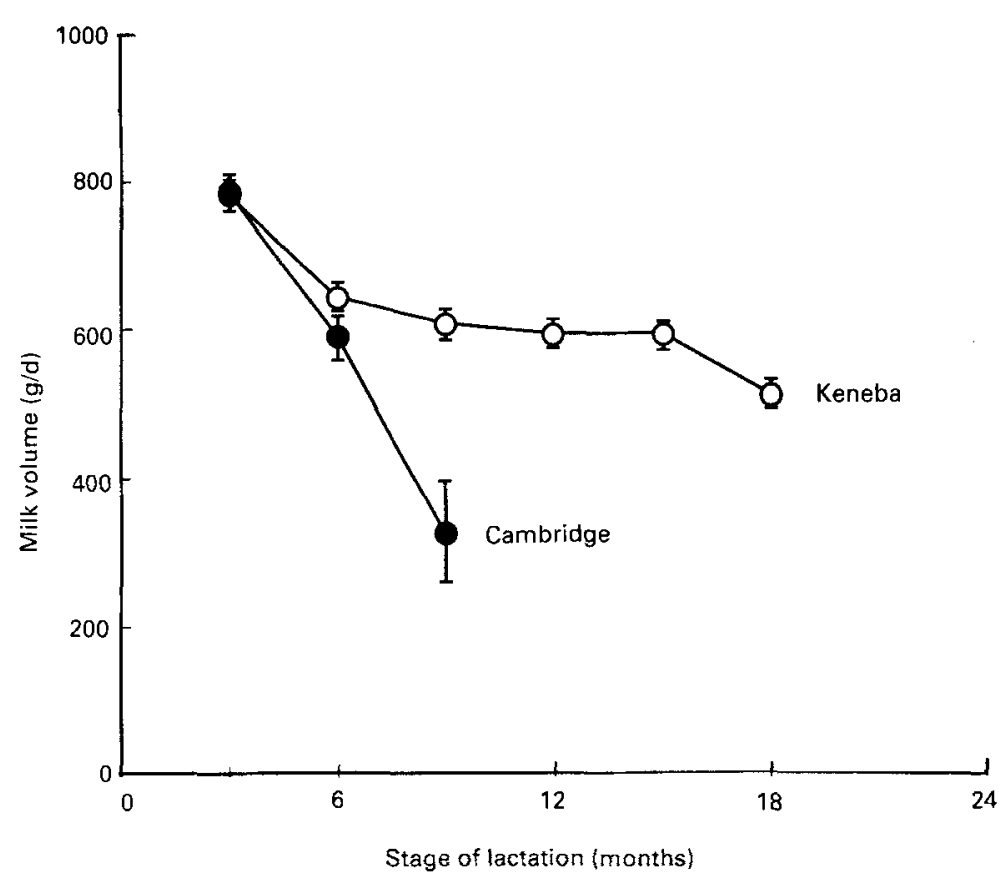

Fig. 5. Milk outputs measured by similar techniques in The Gambia $(O)$ and UK $(\bigcirc)$. Values are means with their standard errors represented by vertical bars. Data from Prentice et al. (1986)
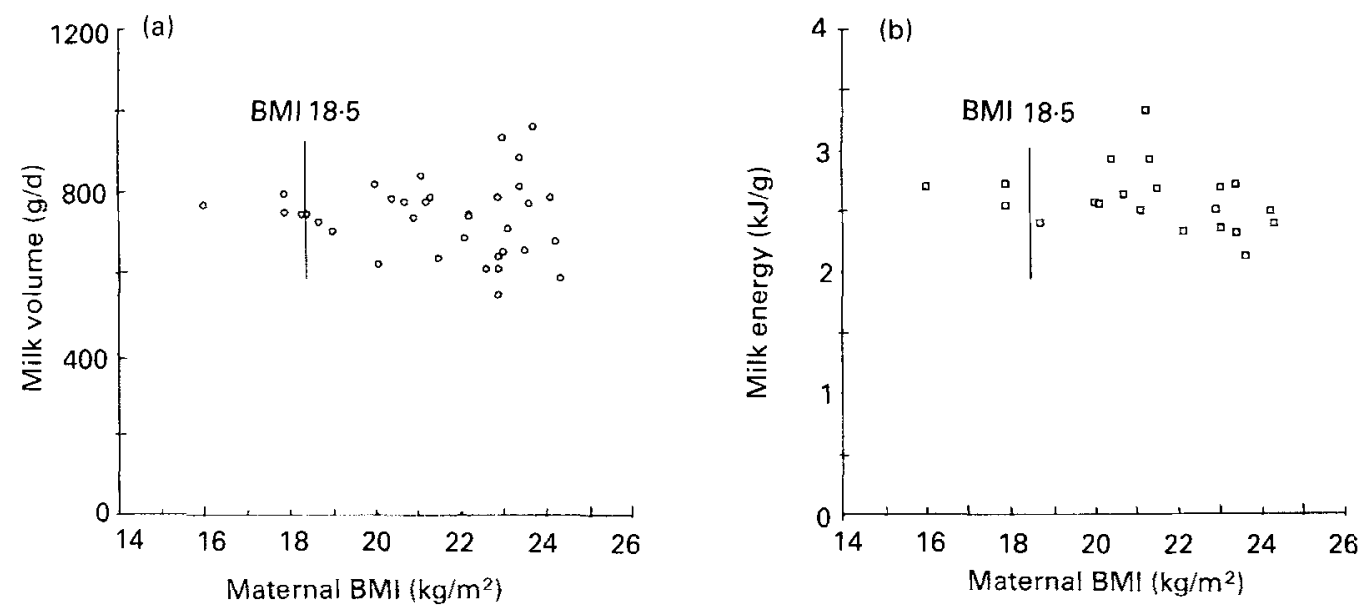

Fig. 6. Relationship between maternal BMI and (a) milk volume and (b) energy content. Data from 1060 women at 3 months postpartum in thirty-five separate studies. Values are means. Data from Zaire excluded. Adapted from Prentice et al. (1994a).

recorded in rural women (approximately $350 \mathrm{~g} / \mathrm{d}$ ) in spite of rather high average BMI. As the data stand out so markedly from the remaining world literature there may be a distinct mechanism at work; either methodological or real. The authors of these reports have suggested that primary protein deficiency may be responsible (Hennart \& Vis, $1980)$. In the remaining data there is no apparent relationship between lactational 

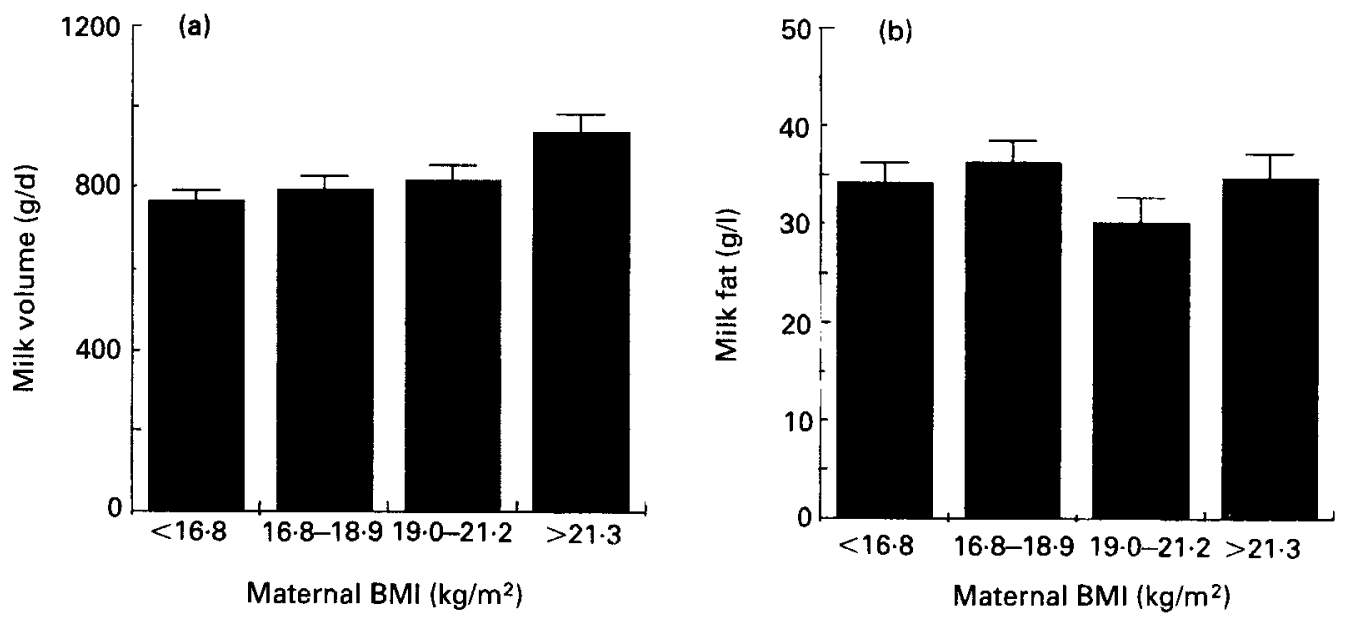

Fig. 7. Relationship between maternal BMI and (a) milk volume and (b) fat content in Myanmar. Burma. Values are means with their standard errors represented by vertical bars. Data from Khin-Maung-Naing et al. (1980).

performance and $\mathrm{BMI}$ even at levels of BMI below $18.5 \mathrm{~kg} / \mathrm{m}^{2}$, normally interpreted as indicating moderately severe chronic undernutrition.

Neither the cross-cultural comparisons in Fig. 4 nor the analysis by BMI in Fig. 6 necessarily confirm that lactation is insensitive to maternal nutrition, since there are many possible confounding differences between such populations. Further analysis is required.

One method is to compare the lactational performance of women of differing nutritional status within the same community. In Keneba, The Gambia, maternal BMI was not significantly correlated with milk output at any stage of lactation (Prentice et al. 1986). In Zaire, irrespective of the concerns about low values, there was no relationship between milk output and BMI in either urban or rural groups (Hennart \& Vis, 1980; Hennart et al. 1983). In Kenya, milk volume was slightly lower $(80 \mathrm{~g} / \mathrm{d}, P<0.028)$ in women classified as WH-minus (mean BMI $18.7 \mathrm{~kg} / \mathrm{m}^{2}$ ) than that in those classified as WH-plus (BMI $23.5 \mathrm{~kg} / \mathrm{m}^{2}$; van Steenbergen et al. 1983), but there was evidence that this result may have been confounded by the fact that infant weight (an important determinant of milk intake) was not included as a covariable (Prentice et al. 1994b). In any case, the milk volumes in both groups were high. In a study from Bangladesh milk volumes were significantly influenced by weight gain in lactation, but not by maternal BMI (Brown et al. 1986). Once again a remarkable feature of the data was the high milk yields in each group. Finally, Fig. 7 shows data from Myanmar, Burma, which include some women at very low BMI (Khin-Maung-Naing et al. 1980). In this study there was a significant positive relationship between BMI and milk volume, but it was caused by an enhanced yield at high BMI rather than by a reduced milk yield at low BMI. Furthermore, all the groups produced remarkably high milk volumes given the small size of the mothers. Even women with a BMI lower than $16.8 \mathrm{~kg} / \mathrm{m}^{2}$ had an average milk yield of $767 \mathrm{~g} / \mathrm{d}$. Elsewhere we have reviewed other studies, including the World Health Organization Collaborative Study on Breast-feeding (World Health Organization, 1985), and concluded that there is little evidence for associations between maternal poverty or undernutrition and the volume of milk produced (Prentice et al. 1986). Indeed milk outputs are often greater in the poor because they are more committed to breast-feeding. 
Perhaps the most robust test of whether or not maternal nutrition influences milk output is to provide a dietary supplement to undernourished mothers and to observe the impact on milk output. Our own studies in The Gambia revealed no effect of a high-energy biscuit supplement which provided a net gain of over $3 \mathrm{MJ} / \mathrm{d}$ (Prentice et al. 1983). Elsewhere we have reviewed other intervention trials and concluded that there is no persuasive evidence of positive effects on total milk energy transfer to the infant (Prentice, 1991).

\section{Influence of maternal nutrition on milk protein and energy content}

The use of different milk-sampling procedures and different analytical methods creates significant difficulties in comparing milk quality between different women. Notwithstanding these problems there is little evidence to indicate important differences in the macronutrient content of milks between well-nourished and undernourished women (Prentice et al. 1986). A possible exception is in the fat (and, hence, energy content) of milk for which there are conflicting results. Studies from The Gambia (Prentice et al. 1981), USA (Nommsen et al. 1991), Mexico (Villalpando et al. 1991) and Bangladesh (Brown et al. 1986) have observed significant positive relationships between milk fat content and various measures of maternal fatness. However, a number of other studies have found no relationships. Of particular interest are the data from Myanmar (Fig. 7) which show no diminution of fat content even at very low levels of maternal BMI (Khin-Muang-Naing et al. 1980). Additionally there are at least two studies which find an inverse relationship between milk fat and maternal nutritional status (van Steenbergen et al. 1983; Marin Spring et al. 1985). Fig. 6 shows that in comparisons between countries there is no apparent relationship between maternal BMI and milk energy content. Most studies of dietary supplementation in lactating women also reveal only trivial effects on milk protein and energy content (Prentice, 1991).

Thus, as in the case of milk volume, the macronutrient content of human breast-milk appears to be surprisingly insensitive to differences in maternal nutrition.

\section{Influence of maternal nutrition on milk vitamin and mineral content}

The influence of maternal nutrition on the vitamin and mineral content of breast-milk is highly variable but is governed by a number of basic principles (Bates \& Prentice, 1988). Water-soluble vitamin content is closely related to maternal plasma levels of the nutrients. Two examples are shown in Fig. 8 which illustrates the marked increase in riboflavin and vitamin $\mathrm{C}$ content of breast-milk in response to programmes of maternal supplementation. Fat-soluble vitamins such as vitamin $A$ are less responsive due to the buffering effects of maternal stores and carrier proteins (Villard \& Bates, 1987). A comprehensive review of the available literature is available (Bates \& Prentice, 1988).

Bates \& Prentice (1988) have also reviewed the influence of maternal nutrition on breast-milk mineral and trace element content. They concluded that breast-milk secretions of $\mathrm{Fe}, \mathrm{Zn}, \mathrm{Cr}, \mathrm{Cu}, \mathrm{Na}, \mathrm{Ca}$ and $\mathrm{Mg}$ do not appear to be related to dietary intake and are likely to be unresponsive to maternal dietary supplementation. Data obtained subsequent to the present review indicate that the behaviour of $\mathrm{Ca}$ is more complex. For instance, our own studies show that Gambian milk Ca levels are much lower than those in Cambridge, but remain unresponsive to dietary Ca supplementation 

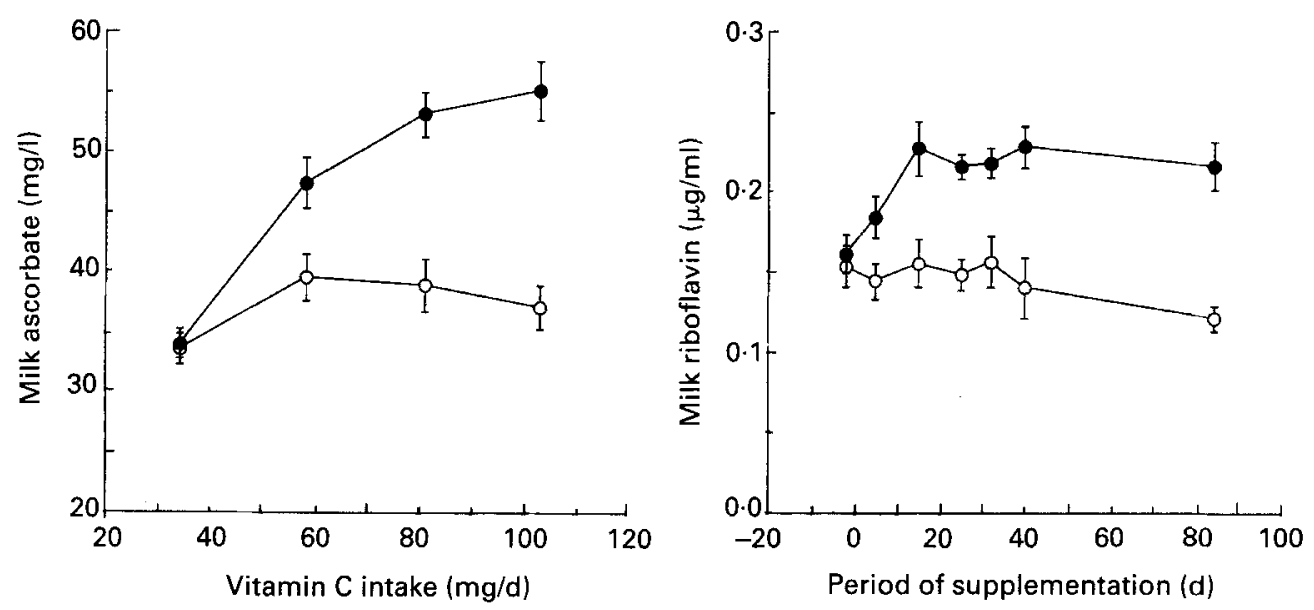

Fig. 8. Effect of dietary vitamin supplementation on the ascorbate (a) and riboflavin (b) content of breast milk. $(\mathrm{O})$, Without supplement; $(\bigcirc)$ with supplement. Values are means with their standard errors represented by vertical bars. Data from Bates et al. (1982) and Bates et al. (1983).

during lactation (Prentice et al. 1994a). In general we conclude that, as with most other components of breast-milk, the most outstanding feature of compositional studies is the fact that milk nutrient levels are well protected.

\section{Conclusions}

Humans have evolved to have very slow rates of infant growth which require a relatively small amount of dilute milk compared with most other mammals. This low stress of lactation affords women with a number of options for protecting milk volume and quality. As a consequence, lactational performance is remarkably unaffected by environmental factors including maternal nutrition, at least at the levels of nutritional status at which studies have so far been performed. This should not be interpreted as indicating that lactating women are not in need of preferential nutritional care. Clearly their nutrient needs are greater than when they are not lactating, and the protection of breast-feeding is often achieved through the depletion of the mother's own body stores. It must also be remembered that there must be a threshold of nutritional status, probably at quite an extreme level of malnutrition, at which the maternal system can no longer sustain lactation and its own survival.

\section{REFERENCES}

Bates, C. J. \& Prentice, A. (1988). Vitamins, minerals and essential trace elements. In Drugs and Human Lactation, pp. 433-493 [P. N. Bennet, editor]. Amsterdam: Elsevier Science Publishers.

Bates, C. J., Prentice, A. M., Prentice, A., Lamb, W. H. \& Whitehead, R. G. (1983). The effect of vitamin C supplementation on lactating women in Keneba: a West African rural community. International Journal of Vitamin and Nutrition Research 53, 68-76.

Bates, C. J., Prentice, A. M., Watkinson, M., Morrell, P., Sutcliffe, B. A., Foord, F. A. \& Whitehead, R. G. (1982). Riboflavin requirements of lactating Gambian women: a controlled supplementation trial. American Journal of Clinical Nutrition 35, 701-709.

Brody, S. (1945). Bioenergetics and Growth. New York: Hafner Press. 
Brown, K. H., Robertson, A. D., Akhtar, N. A. \& Ahmed, M. G. (1986). Lactational capacity of marginally nourished mothers: relationships between maternal nutritional status and quantity and proximate composition of milk. Pediatrics 78, 909-919.

Hennart, Ph., Ruchababisha, M. \& Vis, H. L. (1983). Breast-feeding and post partum amenorrhea in Central Africa, 3 Milk production in an urban area. Journal of Tropical Pediatrics 29, 185-189.

Hennart, Ph. \& Vis, H. L. (1980). Breast-feeding and post partum amenorrhea in Central Africa. 1 Milk production in rural areas. Journal of Tropical Pediatrics 26, 177-183.

Khin-Maung-Naing, Tin-Tin-Oo, Kywe-Thein \& New-New-Hlaing (1980). Study on lactation performance of Burmese mothers. American Journal of Clinical Nutrition 33, 2665-2668.

Marin Spring, P. C., Amancio, O. M. S., Nobriga, F., Araujo, G., Koppel, S. M. \& Dodge, J. A. (1985). Fat and energy content of breast milk of malnourished and well-nourished women, Brazil 1982. Annals of Tropical Paediatrics 5, 83-87.

Martin, R. D. (1980). Adaptation and body size in primates. Zeitschrift für Morphologie und Anthropologie 71, 115-124.

Mepham, T. B. (1987). Physiology of Lactation. Milton Keynes: Open University Press.

Nommsen, L. A., Lovelady, C. A., Heinig, M. J., Lonnerdal, B. \& Dewey, K. G. (1991). Determinants of energy, protein, lipid and lactose concentrations in human milk during the first 12 months of lactation; the DARLING Study. American Journal of Clinical Nutrition 53, 457-465.

Oftedal, O. T. (1987). Milk composition, milk yield and energy output at peak lactation: A comparative review. In Physiological Strategies in Lactation. Zoological Society of London Symposia no. 51, pp. 33-86 [M. Peaker, R. G. Vernon and C. H. Knight, editors]. London: Zoological Society of London.

Prentice, A., Dibba, B., Jarjou, L. M. A., Laskey, M. A. \& Paul, A. A. (1994a). Is breast-milk calcium concentration influenced by calcium intake during pregnancy? Lancet 344, 411-412.

Prentice, A., Prentice, A. M. \& Whitehead, R. G. (1981). Breast-milk fat concentrations of rural African women. 2. Long-term variations within a community. British Journal of Nutrition 45, 495-503.

Prentice, A. M. (1991). Can maternal dietary supplements help in preventing infant malnutrition? Acta Paediatrica Scandinavica 80, Suppl. 374, 67-77.

Prentice, A. M., Goldberg, G. R. \& Prentice, A. (1994b). Body mass index and lactation performance. European Journal of Clinical Nutrition 48, Suppl. 2, 78-89.

Prentice, A. M., Lamb, W. H., Prentice, A. \& Coward, W. A. (1984). The effect of water abstension on milk synthesis in lactating women. Clinical Science 66, 291-298.

Prentice, A. M., Paul, A. A., Prentice, A., Black, A. E., Cole, T. J. \& Whitehead, R. G. (1986). Cross-cultural differences in lactational performance. In Maternal Environmental Factors in Human Lactation. Human Lactation 2, pp. 13-44 [M. Hamosh and A. S. Goldman, editors]. New York: Plenum Press.

Prentice, A. M., Roberts, S. B., Prentice, A., Paul, A. A., Watkinson, M., Watkinson, A. A. \& Whitehead, R. G. (1983). Dietary supplementation of lactating Gambian women. 1. Effect on breast-milk volume and quality. Human Nurrition: Clinical Nutrition 37C, 53-64.

Prentice. A. M. \& Whitehead, R. G. (1987). The energetics of human reproduction. In Reproductive Energetics in Mammals, Zoological Society of London Symposia no. 57, pp. 275-304 [A. S. I. Loudon and P. A. Racey, editors]. London: Zoological Society of London.

van Steenbergen, W. M., Kusin, J. A., de With, C., Lacko, E. \& Jansen, A. A. J. (1983). Lactation performance of mothers with contrasting nutritional status in rural Kenya. Acta Paediatrica Scandinavica 72, 805-810.

Villalpando, S., Butte, N. F., Wong, W. W., Flores-Huerta, S., Hernandez-Beltran, M. de J., O'Brian Smith, E. \& Garza, C. (1991). Lactation performance of rural Mesoamerindians. European Journal of Clinical Nutrition 46, 337-348.

Villard, L. \& Bates, C. J. (1987). Effect of vitamin A supplementation on plasma and breast milk vitamin A levels in poorly nourished Gambian women. Human Nutrition: Clinical Nutrition 41C, 47-58.

World Health Organization (1985). The Quantity and Quality of Breast-milk. Report on the WHO Collaborative Study on Breast-feeding. Geneva: WHO. 